\section{Bioética clínica narrativa}

Autores: Juan Pablo Beca y Mila Razmilic

Editorial Mediterráneo 2014

ISBN 978-956-220-363-0

www.mediterranel.cl

El Dr. Juan Pablo Beca y la Sta. Mila Razmilic, estudiante de Medicina, nos entregan en este libro, a través del relato de casos clínicos reales, una herramienta metodológica valiosa para la toma de decisiones. Se introduce el contexto global, las contingencias que lo rodean y las emociones de todos los involucrados como parte importante en el proceso deliberativo, tanto personal como grupal.

Los casos clínicos reales nos enfrentan no sólo a decisiones técnicas sino que también a problemas éticos. La sociedad contemporánea plural, con valores en algunos casos no compartidos, en que las personas tienen derechos reconocidos para tomar decisiones sobre sí mismos, enfrenta a los profesionales de la salud a escenarios previamente desconocidos a los cuales debemos sumarnos con humildad por respeto a nuestros pacientes. Las decisiones técnicas en la medicina actual pueden ser difíciles y requerir de la opinión de varios especialistas antes de instalar una terapia. Las decisiones clínicas tienen a su vez aspectos éticos que se deben considerar y reflexionar, tomando en cuenta los valores en juego de todos los involucrados y los fundamentos éticos que sustentan cada acción.

La toma de decisiones frente a nuestros pacientes requiere hoy formación acabada en análisis, reflexión y deliberación bioética. Como expresa el Dr. Beca en la presentación del libro, el propósito es ofrecer casos para la enseñanza y el aprendizaje de habilidades de deliberación en Bioética.

La primera parte del libro contiene una Guía pedagógica para la utilización de las narraciones, escrita por la Magíster en Educación Josefina Santa Cruz, la que describe diferentes estrategias de enseñanza de gran utilidad para la docencia en general. La recomendación de los autores de leer cada caso y realizar una deliberación (personal o grupal) antes de leer el análisis bioético es condición importante para el aprendizaje que se logra con este libro.

Los capítulos 1 al 10 corresponden cada uno a un caso con su respectivo análisis bioético realizado por un especialista, participando seis autores de capítulos, además de los editores del libro.

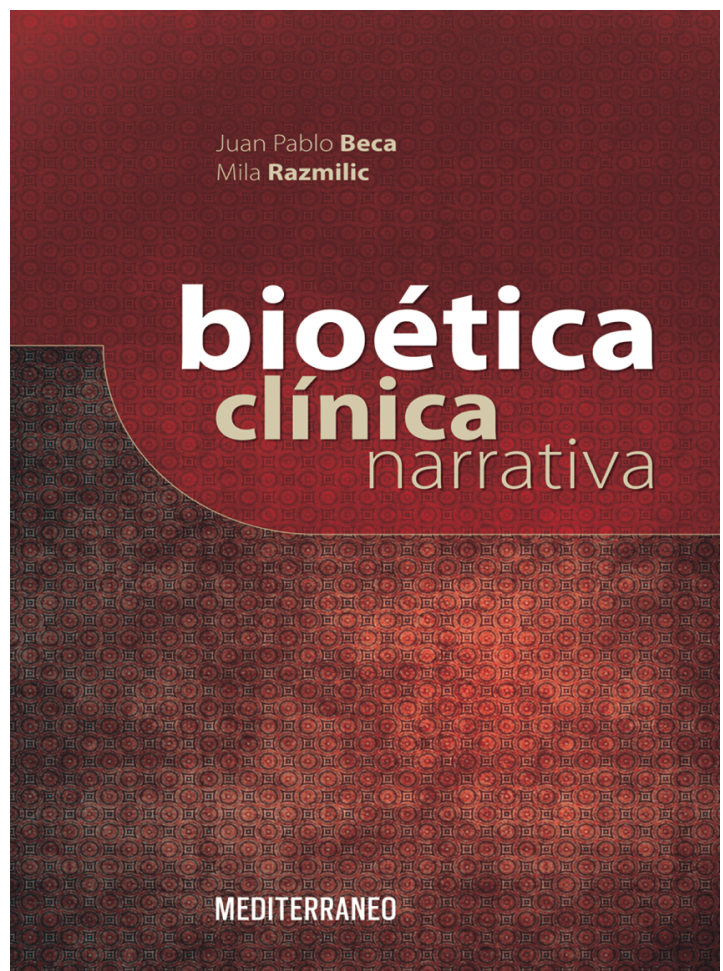

Este análisis no pretende agotar toda la riqueza de temas para deliberar qué presenta cada caso, los que sí son listados en la primera página de cada capítulo.

Los capítulos que conforman el libro son: Aborto, Limitación del esfuerzo terapéutico, Retardo mental, Enfermedad terminal, Donación de órganos, Rechazo de tratamiento, Muerte digna y derecho a morir, Decisiones al final de la vida y envejecimiento satisfactorio, y Voluntades anticipadas.

Este libro nos da la oportunidad de vivenciar casos reales a través de una narración enérgica y potente en lo humano y lo contextual, con los que podremos tener un buen ingrediente para la enseñanza del análisis bioético.

El libro Bioética Clínica Narrativa será un gran aporte para la docencia de la bioética en las distintas etapas de las carreras de la salud y también para los profesionales que quisieran ejercitar su metodología de análisis bioético.

Dra. Carmen Paz Astete A. Facultad de Medicina, Clínica Alemana-Universidad del Desarrollo. Santiago de Chile. 